\title{
Narradoras mexicanas del modernismo: las tribulaciones editoriales de Betanzo, Méndez y Camarillo
}

\section{Mexican Feminine Narratives in "Modernismo": Betanzo's, Méndez's and Camarillo's Publishing Tribulations}

\author{
Dolores Phillipps-López \\ Universidad de Lausana / Universidad de Ginebra \\ Dolores.Phillipps-Lopez@unil.ch
}

\section{RESUMEN}

Con ecos raros y someros de sus publicaciones (tres novelas y tres novelas cortas) en la prensa de la época, algunas obras hoy desperdigadas en escasas bibliotecas y una recepción crítica actual reducida a dos o tres incursiones menores en su obra, Francisca Betanzo o Chanteclair, nacida en Tehuacán, presenta un caso significativo, sin duda extremo, entre los de aquellas mujeres mexicanas dedicadas a la literatura durante el fin de siglo porfiriano modernista: es la suya una historia más "de zozobra y desconcierto" (Romero, 2015). Comparando la coincidencia de su nombre con los de las escritoras mexicanas Laura Méndez y María Enriqueta Camarillo bajo idénticos sellos editoriales parisinos (Paul Ollendorff y Vda. de Ch. Bouret), se examinarán las divergentes circunstancias que precedieron a la inclusión, a inicios del siglo xx, de sus respectivas obras en los catálogos de estos dos famosos editores-libreros de la época. El enfoque de las olvidadas narraciones de Francisca Betanzo bajo el prisma de la edición, difusión y recepción tratará de proveer argumentos para un rescate de las obras de esta escritora tehuacanense olvidada.

\section{Palabras clave}

Francisca Betanzo, Laura Méndez, María Enriqueta Camarillo, modernismo mexicano, editoriales, género, rescate.

\section{ABSTRACT}

With rare and brief echos of her published work (three novels and three short novels) in the press of her time, few books scattered today in a couple of libraries and present critical reception reduced to two or three minor incursions of her work, Francisca Betanzo (Chanteclair), born in Tehuacan, is a revealing - although ex- 


\section{|Dolores Phillipps-López}

treme - case among those Mexican women devoted to literature during the Modernist fin de siècle of the Porfirian regime. More than anything else, hers is a story of "uncertainty and perplexity" (Romero Chumacero, 2015). Due to the fact that the works of Francisca Betanzo were published simultaneously with those of Mexican writers Laura Méndez and $\mathrm{M}^{\mathrm{a}}$ Enriqueta Camarillo in identical publishing houses in Paris (Paul Ollendorff and Vda. De Ch. Bouret), particular attention will be given to the different circumstances that led to the inclusion, at the beginning of the xx century, of their respective works in the catalogs of these well-known Parisian publishers of the time. The approach of the forgotten texts of Francisca Betanzo from the perspective of publishing, distribution and reception of her work is an attempt to provide arguments in favor of rescuing the works of this forgotten Tehuacan writer.

\section{KEYWORDS}

Francisca Betanzo, Laura Méndez, María Enriqueta Camarillo, Mexican modernism, publishing agencies, gender, rescue.

\section{RECEPCIÓN: 13/05/2019}

ACEPTACIÓN: 24/06/2019

G n 1995, el librero, editor y poeta sevillano Abelardo Linares adquirió los fondos _- "más de un millón de volúmenes" - de la librería del fallecido exiliado gallego Eliseo Torres, situada en el Bronx, Nueva York. ${ }^{1}$ Con la llegada a la Universidad de Ginebra de un deslumbrante catálogo de la librería "Renacimiento", propiedad de Linares, que consignaba ya más de 13000 títulos de literatura hispanoamericana desprendidos de los fondos recién trasladados a Sevilla, pudimos descubrir el nombre de Francisca Betanzo, seguido del apodo literario Chanteclair, y conseguir los dos libros - intonsos - que de ella se ofrecían: La peña del infortunio (París: Librería Paul Ollendorff, 1910) ${ }^{2}$ y Asceta y suicida (París: Ollendorff, 1912), ${ }^{3}$ con dedicatoria al presidente "Don Francisco Madero", los cuales resultaron ser de una desconocida narradora mexicana del modernismo. Un tercer volumen de su autoría, Brumas alcohólicas - no-

1 Véase página principal de la librería en: http://www.libreriarenacimiento.com [04/04/19].

${ }^{2}$ Volumen sin fecha de edición. Suscrito en "París, a 16 de julio de 1909". Como lo detalla Jean-François Botrel en su indispensable estudio (1970: 27), este libro se editó en septiembre de 1910.

${ }^{3}$ Sin fecha de edición. Suscrito en "París, febrero de 1911". También, en este caso, Botrel (1970: 27) indica la fecha precisa de edición: febrero de 1912. 
vela seguida de la novela corta $A$ sangre y fuego-, publicado en Barcelona (Francisco Granada y C. ${ }^{a}$ hacia ¿ 1912?), ${ }^{4}$ si bien suscrito el 26 de agosto de 1909, vino luego a completarlos (un libro del que pudimos primero sacar fotocopias en la biblioteca del Instituto Iberoamericano de Berlín y después adquirir).

Nuestro muy reciente hallazgo, en una librería de viejo uruguaya, ${ }^{5}$ del cuarto libro editado de Betanzo que juzgábamos perdido, La modelo. La insaciable, dos novelas cortas publicadas en 1909 en París/México, bajo el sello de Vda. de Ch. Bouret, con la exclusiva mención de su pseudónimo, Chanteclair, ${ }^{6}$ nos ha animado a retomar los resultados que obtuvimos de un primer acercamiento en 2001 dedicado al singular - hasta hoy persistente - anonimato de la obra de esta narradora (véase PhillippsLópez).

Aunque el volumen de sus respectivas obras, así como su calado en la historiografía y la crítica literarias las haga incomparables, proponemos centrarnos en la coincidencia del nombre de Betanzo, bajo idénticos sellos editoriales parisinos, con los de dos escritoras mexicanas, como ella, viajeras y cosmopolitas, Laura Méndez de Cuenca y María Enriqueta Camarillo y Roa de Pereyra, cuyas contribuciones literarias y periodísticas, ya por entonces, habían logrado emerger junto a las de Gutiérrez Nájera, Gamboa o Nervo. Al decir de Mílada Bazant, "publicar con Ollendorff no era cualquier cosa" (2013a: 303); ${ }^{7}$ de hecho, Paul Ollendorff fue editor en 1910 de los cuentos de Méndez, maliciosamente titulados Simplezas, que llegaron a posicionarse entre los 118 títulos de los "escritores de lengua española" publicados entre

\footnotetext{
${ }^{4}$ En la contraportada de Brumas alcohólicas, entre diversos títulos declarados "del autor", figuran La peña del infortunio de 1910 y Asceta y suicida de 1912, por lo que indicamos ¿1912? como fecha aproximada de publicación.

${ }^{5}$ Se trata de "Calle Puan. Librería online" de Montevideo: http://dixegno.wix.com/callepuan y https://callepuan.webnode.com.uy [04/04/19].

${ }^{6}$ Este libro se publicita con letras capitales y como "Novedad", "Un tomo en 8०, Ptas. 2", en un periódico catalán, a 3 de septiembre de 1909 (La Esquella...: 583).

${ }^{7}$ Aprovechemos para subsanar dos leves confusiones. Por un lado, Bazant afirma que "la compilación de cuentos, Simplezas" salió "tanto en París como en Viena" (2013a: 303). Hay que precisar que Viena corresponde, en el caso de este libro, a un departamento francés de la región Poitou-Charentes, y no a la capital de Austria. En efecto, en dicho volumen de Méndez, con sello de Ollendorff, se indica "Impreso por Eugenio Aubin.- Ligugé (Vienne)" (1910: 270). En la pequeña municipalidad de Ligugé, Dpto. de Vienne, algunos monjes benedictinos fundaron un taller de imprenta en 1891, luego "Imprimerie Aubin", cuya actividad prosigue hoy con la impresión de los libros de la editorial parisina Odile Jacob y los de la prestigiosa colección de "La Pléiade" (véase: aubinimprimeur.fr). Por otro lado, Bazant sostiene que el mexicano Justo Sierra fue publicado en Ollendorff (2013a: 303); no obstante, el dato no consta en el exhaustivo estudio de Botrel (1970). En cambio, la casa Bouret sí editó la obra de Sierra.
} 


\section{|Dolores Phillipps-López}

1906 y 1916 por la Sociedad Ollendorff, ${ }^{8}$ de los cuales 115 corresponden a plumas masculinas; ${ }^{9}$ a éstos se añaden seis títulos más, editados a cuenta de autor, entre los que figuran La peña del infortunio y Asceta y suicida de Francisca Betanzo. Dichas cifras fueron consignadas, con ejemplar minucia, en 1970 por el hispanista y especialista de la historia del libro Jean-François Botrel en su decisivo estudio sobre la actividad - registro de contratos incluido- de La "Sociedad de ediciones literarias y artísticas-Librería Paul Ollendorff".

Por su parte, la editorial Vda. de Ch. Bouret, la "más conocida de México en el Porfiriato" (Suárez: 87), casa asentada en París - al igual que en México - desde hacía varias décadas (Fernández, 1998: 174-176) y que ejercía en "la edición escolar, religiosa, tecnológica y clásica una suerte de monopolio" (Botrel, 1970: 15), ${ }^{10}$ asume la publicación, en 1914, ${ }^{11}$ de los cinco primeros libros de lectura Rosas de la infancia, preparados por Camarillo para la escuela primaria, cuyo perdurable éxito es sobradamente conocido: "Su clásico infantil Rosas de la infancia educaría - desde 1914 hasta la década de 1970 - a varias generaciones de niños y niñas mexicanas por todo el territorio nacional, formándolos en valores y virtudes como la ciudad letrada, el sentido común y comunitario, la civilidad" (Granillo: s. p.).

Nuestra intención es, por tanto, examinar — bajo el prisma selectivo de la edición, difusión y recepción - las divergentes circunstancias que precedieron a la inclusión de las obras de Betanzo, Méndez y Camarillo en los catálogos de estos dos famosos editores-libreros de la época que, junto a Garnier Hnos., Louis Michaud y Armand Colin, y hasta la Primera Guerra Mundial en 1914, hicieron de París una de las capitales dominantes de la edición en lengua española, fecha en la que "las colecciones españolas [de los editores franceses] fueron las primeras sacrificadas" (Botrel, 1970: 3).

Los únicos detalles biográficos disponibles hasta hoy acerca de Francisca Betanzo los apuntaba ya en 1926 Juan Bautista Iguíniz en su conocida Bibliografia de novelistas mexicanos:

${ }^{8}$ Botrel apunta 115 títulos (1970: 2 y 8), pero nuestro recuento suma 118. Al lado de este excepcional estudio de Botrel sobre la actividad editorial francesa en América Latina, con muy indispensable documentación para el caso de México, véanse Botrel (1997 y 2001), Fernández (1998) y Cooper-Richet (2013), entre otros.

${ }^{9}$ Las dos únicas autoras publicadas por Ollendorff, a cargo de la editorial, fueron, además de Laura Méndez, Blanca Z. de Baralt (abril de 1914) y Adela Zamudio (junio de 1914) (véase Botrel, 1970: 23 y 26).

${ }^{10}$ Tanto ésta como las siguientes traducciones del presente trabajo son nuestras.

${ }^{11}$ La fecha de 1914 es la que generalmente se indica, sin otras precisiones. En nuestra bibliografía final, no obstante, consta 1913 como el año de publicación del libro primero de Rosas de la infancia, pues retomamos los datos propuestos por Ziga Espinosa (182), quien regista 1914 para el "libro cuarto" (181). No pudimos conseguir los datos de los libros segundo, tercero y quinto de la edición de Bouret. 


\section{Narradoras mexicanas del modernismo}

Betanzo, Francisca. Es originaria de Tehuacán, importante población del Estado de Puebla, donde se educó. Ha vivido algunos años en España y Francia consagrada al periodismo, y ha escrito y publicado varias novelas, algunas de ellas de un naturalismo crudo y de atrevidas ideas. Partidaria acérrima de las ideas ultramodernistas, ha propugnado y difundido en sus escritos la emancipación de la mujer (42). ${ }^{12}$

La lectura de los relatos de Betanzo confirma las notas de Iguíniz. En cambio, no logramos documentar su actividad periodística en México, París ni Barcelona, pero no cabe duda de que cierto sensacionalismo y tono polémico dan pulso periodístico a su escritura y que la boyante prensa de aquel entonces nutre su imaginario novelesco al movilizar acontecimientos de la vida política, social y cultural más inmediatos de París, Barcelona o México (ecos del affaire Steinheil, que involucraba a la antigua amante del presidente Félix Faure, semana trágica barcelonesa, transición de Porfirio Díaz a Francisco Madero, etc.), recortes reales o ficticios de periódicos (Le Journal de París; El Mundo, El Imparcial, El Monitor Republicano de México), sin olvidar los vehementes exabruptos autorales acerca de la responsabilidad pública compartida de políticos y periodistas.

Las obras de Francisca Betanzo son de un indudable valor para el conocimiento y la comprensión de la situación de los artistas en la sociedad burguesa moderna hispanoamericana, de manera más precisa, la de un sector muy marginado de sus representantes, pues constituyen un testimonio narrativo femenino; pero, además, la trayectoria documentable de Betanzo en la práctica de la profesión de escritora, por breve que haya sido, resulta doblemente ejemplar. Traduce la naturaleza ambigua de las relaciones entre escritores y editores (la mercantilización del arte) en el contexto europeo de la consolidación del capitalismo hacia los años 1880-1920 (véase Mollier). Asimismo, las novelas de Betanzo, al oscilar entre ostensivo desprejuicio y demolición frontal, se revelan desmitificadoras respecto de los hipócritas conformismos religiosos, sociales (sexualidad femenina, aborto y violencia de género incluidos) y políticos, y desmienten cierta idea difundida por Jean Franco - su ensayo Las conspiradoras, de 1994, es un ejemplo_-, según la cual las escritoras burguesas del Porfiriato, como productos de éste y reproductoras de los valores de su clase, ya fuera que adoptaran "una máscara de ingenuidad e infantilismo, aceptando una posición subordinada" (136), ya que expresaran el descontento ante la condición femenina y ante las dificul-

${ }^{12}$ Estas indicaciones, resumidas, son las que constan hasta hoy en la Enciclopedia de la literatura en México (elem.mx). Véase "Francisca Betanzo". Sólo podemos añadir a estos datos biográficos el detalle que encontramos en la nota "Velada en Tehuacán", publicada en La Voz de México del 20 de septiembre de 1900, en la que se da noticia del evento organizado el 18 del mismo mes en honor de la llegada del "Ilmo. Sr. Arzobispo Gillow", y consta lo siguiente en su programa: “Ave María de Otelo', cantada por la Srita. Francisca Betanzo y acompañada en el piano por el Sr. Francisco Molano” (3). 


\section{|Dolores Phillipps-López}

tades de vida de las clases sociales modestas, pero lo hicieron "a cubierto de la crítica seria", por lo que sus temas reflejaron "tímidamente una falta de conformidad con la domesticación", tratando "de manera indirecta sobre la emancipación femenina" como "tímida rebelión apenas musitada" (136-137).

En el primero de los casos, Franco se refiere a María Enriqueta Camarillo, católica y conservadora, escritora mexicana prolífica y, probablemente, la más citada y estudiada, durante mucho tiempo, entre las narradoras modernistas de Hispanoamérica; en el segundo, el estudioso alude a la lectura de los cuentos muy ponderados en sus reclamos emancipadores que Laura Méndez reunió y tituló Simplezas.

El reconocimiento del positivo "feminismo precoz", "subversivo", "pionero" o "solidario" de la obra de Méndez en general es hoy la línea que siguen investigadoras como, respectivamente, Glantz (2011), Montero (2002), Bazant (2013b) y Romero Chumacero (2011), quienes la documentan de manera profusa. No obstante, en el siglo xxi, el balance de la participación de las escritoras del Porfiriato en el combate por la causa femenina o de otros sectores marginados no parecería superar aquella "tímida rebelión apenas musitada", esto es, el recato que Franco observa en las Simplezas de Méndez. Previsiblemente, lejos de emancipar, la fórmula (pseudo)auto-despreciativa elegida por la escritora para titular sus narraciones - ya fuera "treta del débil" (véase Ludmer) o "retórica de la humildad" (Romero, 2008: 112 y 2015: 171) — desató o reforzó condescendientes actitudes hegemónicas en alguno que otro reseñista, como Ramón María Tenreiro, quien en una revista madrileña de septiembre de 1910, y con muy irónico retintín, consideraba:

Simplezas. - ¿Qué le voy a hacer yo? La autora de estos cuentos calificalos de "simplezas" (sin perjuicio de poner su retrato en la primera página) y tratándose de una dama, no hay remedio sino exclamar: — ¡Por Dios, señora mía! ¡no diga usted disparates! ¡si estos relatos parecen escritos por la propia musa de la discreción! Y la verdad es que la autora peca de modesta al titularlos Simplezas. No todos lo son [...] y aunque no tienen esa plasticidad, esa fuerza casi dramática, propia del cuento, no dejan de leerse con agrado (295-296).

En lo que concierne a María Enriqueta Camarillo, contrastando con su importante visibilidad pública e institucional, se subraya una ausencia o, en términos de Ana Rosa Domenella, una "mezcla de ceguera histórica y puerilidad vital", que tienen "su fundamento en valores patriarcales, eclesiásticos y moralizantes que están presentes a lo largo de su obra poética y narrativa" (1991: 21). ${ }^{13}$

Francisca Betanzo, por su lado, adoptó el seudónimo literario de Chanteclair en todas sus publicaciones. En su primer libro de 1909, La Modelo. La Insaciable, lo

\footnotetext{
${ }^{13}$ Comparten esta apreciación estudiosas como Evangelina Soltero Sánchez y Esther Hernández Palacios.
} 
inscribió en un gesto autorial aún retraído o, quizá, como clandestinidad estratégica que atizara las promesas algo morbosas y transgresivas del título, a tono, desde luego, con la disipación de la efervescente y permisiva Belle Epoque parisina. Con ese sobrenombre, la escritora reivindicaba su vinculación con el contexto de la cultura francesa - francofilia compartida por no pocos escritores hispanoamericanos del modernismo-- pero, a pesar de que la ironía de la fortuna literaria la convirtió en una de las autoras más amordazadas del Porfiriato, Betanzo pronto se dispuso a asumir expresamente la responsabilidad moral (y hasta política) que implicaba su seudónimo. En mitad de su novela La peña del infortunio, de 1910, la autora prorrumpe:

¿Qué hacéis señores periodistas? ¿Qué hacéis señores gobernantes [...]? ¿Qué tenemos que hacer los periodistas? ¿Qué los gobernantes? No olvidéis que mi nombre es Chanteclair. Canta Claro, y, por lo tanto, haciendo uso de los derechos de pluma inserto en ésta vuestros deberes. [...] Si queréis que os lean, enseñad a leer, y si queréis lectores procuradlos, y así que éstos comprendan vuestras ideas, difundidlas [...].

Para educar hombres se necesitan mujeres. Cuando la mujer sea fuerte, hará corazones en los hombres [...], cuando los hijos vean estimadas a sus madres ellos estimarán a sus mujeres; para que éstas sean estimadas deben hacerse valer. ¿Cómo? Destruyendo los principales defectos que nos elogian los hombres para matar nuestra energía moral. ¡Abajo la vanidad, la hipocresía, nerviosidades, ignorancia y dramaticismos!

[Tal] es el remedio que imponéis; la continuidad: ¡Marido! ¡marido! [...]: ;la perpetuidad de las desgracias! [...] (167, 170, 261 y 321; las cursivas son de la autora).

Por contraste, nos parece bastante superficial uno de los dos únicos ecos periodísticos que dio fe de la muy escueta recepción de la novela de Betanzo, La peña del infortunio: ${ }^{14}$ apareció un año y medio después de publicarse la novela, nada menos que

${ }^{14}$ Dejando aparte lo referido a La peña del infortunio, la acogida de la intervención literaria de Betanzo se reduce a una que otra ocurrencia de su nombre en publicaciones periódicas de inicios del siglo xx. Tal es el caso de la revista parisina Les Annales Politiques et Littéraires del 2 de enero de 1916: "Nous nous plaisons à signaler, entre autres, le vif intérêt des contes, récits ou articles signés des noms qui suivent" (25) ["Nos complacemos en señalar, entre otros, el vivo interés de los cuentos, relatos o artículos firmados por los nombres que siguen"], y, entre más de treinta nombres, figura el de "Francisca Betanzo". Más sorpresiva resulta su colocación - ;como ensayista! - dentro de lo más granado de la literatura mexicana de la época en el recuento realizado en 1922 por el romanista austriaco Martin Brussot: "Als Erzählerin bodenständiger Geschichten, bunt und seltsam zugleich, besitzt Laura Méndez de Cuenca Bedeutung; Amando [sic] Nervo erweist sich als origineller Novellist und Lyriker, Francisca Betanzo schreibt Essais, ähnlich Alfonso Reyes, Justo Sierra, Gustavo E. Campa und Emilio Rabasa" (755) ["Como narradora de cuentos coloridos a la vez que extraños, Laura Méndez de Cuenca es una figura importante; Amando (sic) Nervo destaca como novelista y poeta original, Francisca Betanzo escribe ensayos, como Alfonso Reyes, Justo Sierra, Gustavo E. Campa y Emilio Rabasa"]. 


\section{|Dolores Phillipps-López}

en la revista Mundial Magazine, editada en París y cuya dirección literaria perteneció, como se sabe, al renuente Rubén Darío. ${ }^{15}$ En la sección denominada "Libros hispanoamericanos" de abril de 1912, ${ }^{16}$ leemos:

La peña del infortunio, por Francisca Betanzo ("Chantecler"). Librería Paul Ollendorff, París. Un grueso volumen de más de trescientas páginas, esmeradamente editado por la conocida librería de la "Chaussée d'Antin"; dentro de este grueso tomo hay una novela escrita con esmero por la señora Doña Francisca Betanzo, cuyo título es La peña del infortunio (590).

Ya el viernes 2 de diciembre de 1910, a los dos meses de haber salido a la luz y tras difundirse en México, esta misma novela había provocado un tajante rechazo, descaradamente misógino, de parte de un reseñista anónimo, quien - habitual paradoja - se mostró prolijo en el comentario que redactó para el diario católico fundado por Victoriano Agüeros, El Tiempo:

"Francisca Betanzo (Chanteclair).-La peña del infortunio.-Librería Paul Ollendorff. -50, Chaussée d'Antin, París".

Allá en una época quizá algo lejana un Adolfo Carrillo, y un periodista que todavía vive, presentaban en sus periódicos verdaderas difamaciones, pero escudándose, sustituyendo los nombres de algunos personajes de aquella época con otros supuestos.

En esta novela se encuentra la misma tendencia que la de aquellos periódicos, que en mala hora ejercieron el "chantage".

En esta novela se revela la idea de presentarnos como una sociedad completamente perdida.

¡Qué equivocada anda la autora o autor[!] (¡quién sabe quién podrá ser sirviéndose de un seudónimo!)

En México, no obstante la corrupción que invade al mundo, todavía hay almas buenas. Esta obra que hemos recibido, casi nos causa náuseas.

La autora habla del Divino Jesús, queriéndose colocar a la altura de un predicador. Es iconoclasta, es enemiga de las imágenes. Habla como una Luisa Michel.

La imagen de Jesucristo, muy señora nuestra, se debe respetar.

¿Gustaría a Ud. que el retrato de su padre fuera despreciado?

Pocas, muy pocas mujeres tienen buen criterio para escribir.

Aquí en México ya existe casi como proloquio un dístico que se aplicó a una escritora que nos visitó, hace algún tiempo.

Era casada y se decía de ella lo siguiente, sin nombrar al marido:

${ }^{15}$ No muy convencido por esta empresa literaria y de actualidad, más que nada comercial, a la que se añade la revista gemela Elegancias, Darío expresó su disgusto en 1912 en su Epistolario: "esta cosa de Mundial y Elegancias en donde, no hay duda, ganaré algo para la vida, pero en la cual, mi buen gusto suda y mi dignidad corcovea" (Darío citado en Molloy: 46).

${ }^{16}$ Antes de proceder a la consulta de este número de Mundial Magazine, hemos conseguido la localización exacta en el libro de Hernández de López (332). 


\section{Narradoras mexicanas del modernismo}

“¡Concepción, Concepción, no desatines[!] Remienda a tu señor los calcetines". ${ }^{17}$

Y hemos concluido al hablar de esta obreja ("Bibliografía...": 8).

Volvamos ahora a aquella singular coincidencia de 1910. La tirada de Simplezas en Ollendorff se negoció en el mes de abril de 1910, ${ }^{18}$ y los cuentos salieron en junio de ese mismo año. El 11 de abril de 1910, precisamente, se le dio a Francisca Betanzo, en la misma editorial Ollendorff, el presupuesto de elaboración de La peña del infortunio, que se imprimió en el mes de septiembre de ese año. Laura Méndez obtuvo el privilegio de un tiraje de 1650 ejemplares, cuyos gastos asumió enteramente la editorial, ${ }^{19}$ pero, a cambio, cedió todos los derechos de propiedad de su obra por 400 francos de la época (hoy cerca de 1800 dólares); ${ }^{20}$ cesión que, en caso de éxito seguido de reedición para hispanohablantes o éxito seguido de traducción para un público francófono, favorecería en primera instancia a la sociedad editora, pues, como indica Botrel, en Ollendorff se tenía "una idea bastante justa de las posibilidades reales de venta de las obras de escritores de lengua española" (1970: 11).

Francisca Betanzo, por su lado, publicó a cuenta de autora 1000 ejemplares de $L a$ peña del infortunio, que salió en septiembre de 1910, y por los que pagó la considerable suma de 1709 francos (cerca de 7770 dólares). Las mismas gestiones se repiten para su segunda novela; según indica Botrel (1970: 27), negociada en octubre de 1911, Asceta y suicida se editó en Ollendorff en febrero de 1912. ${ }^{21} \mathrm{Su}$ tirada fue inferior (500 ejemplares), también a cuenta de autora (532 francos, cerca de 2418 dólares), aunque

${ }^{17}$ El reseñista alude aquí a Concepción Gimeno de Flaquer, quien "dirigió una revista en México Distrito Federal, donde se instaló entre los años 1883 y 1890: El Álbum de la Mujer" (Servén: s. p.). García Barragán transcribe el zahiriente dístico: “[i] Concepción, Concepción, no desatines!/ Remiéndale a Flaquer los calcetines" (50).

18 Tanto éste como los siguientes detalles contractuales de Ollendorff constan en Botrel (1970).

${ }^{19}$ Se rectifica, así, la conjetura sobre una publicación de Simplezas a cuenta de la propia Laura Méndez, presente en Domenella y Gutiérrez: "Simplezas se publica en París, en 1910, posiblemente en edición de la autora" (193; las cursivas son nuestras), y también en Fernández: "[E]n 1910 había hecho imprimir a sus costas, en París, su libro de cuentos Simplezas" (2014: 163; las cursivas son nuestras).

${ }^{20}$ Partimos del cálculo del poder de compra de 1910 en Francia, que tiene en cuenta la erosión monetaria debida a la inflación: 400 francos franceses antiguos equivalen a unos 1543 euros de hoy, que convertimos en dólares (véase INSEE).

${ }^{21}$ En su tercera plana, Asceta y suicida lleva la siguiente dedicatoria: "Al señor Presidente de la República de los Estados Unidos Mexicanos don Francisco J. [sic] Madero". La historia se desarrolla en la Tehuacán natal de la autora y sus alrededores. Se trata de una novela psicofilosófica, en la que se plantean las contradicciones entre modos del conocimiento (experiencia sensible, ciencia, religión), alegorizadas en la trayectoria vital de un protagonista masculino escindido interiormente. 


\section{|Dolores Phillipps-López}

con mejores perspectivas en caso de reimpresión, ya que, si procediera, el editor se comprometía a pagar los gastos.

Entre La peña del infortunio y los cuentos de Méndez, el colaborador anónimo que redactó aquella pálida reseña en Mundial Magazine se inclinó por publicitar la obra de Betanzo. ¿Pensaría, en aquel mes de abril del año 1912, en plena presidencia de Francisco I. Madero en México, que el trasfondo geográfico e histórico de la obra (Oaxaca, Tehuacán, México, París, etc., 1908-1909), el anticlericalismo reiterado y combatiente - tan 'revolucionario' de su autora-, su afiliación estética al decadentismo de cuño naturalista, aún en boga, y sus ideas progresistas en torno a las relaciones entre mujeres y hombres auguraban éxito para La peña del infortunio? Evidentemente, subsisten dudas sobre las razones que motivaron la promoción de la novela de Betanzo en la revista parisina. Referido a "una novela escrita con esmero por la señora Doña Francisca Betanzo" ("Libros...": 590), el vacuo comentario del reseñista ni siquiera da fe de una efectiva lectura del libro, y tampoco se pueden excluir eventuales y persuasivos ruegos de la propia autora.

Contrariamente a la anónima Betanzo, a la hora de negociar con Ollendorff las condiciones de edición de Simplezas — ganadas a pulso con "agallas varoniles"—, ${ }^{22}$ Laura Méndez disponía de una "superficie social" (Habib: 31), o sea, de visibilidad en una compleja red social, la cual se requería para enfrentarse a la institución literaria, así como de aptitudes de agente comercial.

Laura Méndez, llegada en 1910 a sus 57 años y ya por entonces "escritora muy aplaudida" (Martínez y Mejías: 77), con aura de "famosa" y de personaje público entre las expatriadas hispanoamericanas presentes en Europa, gozaba de una notoriedad indiscutible como especialista en cuestiones de organización de la enseñanza y de la pedagogía, representante de México con respecto a estas materias en numerosos congresos europeos; además de periodista prolífica y talentosa, era poeta antologada - rara consagración institucional, vale decir, masculina - por Juan de Dios Peza, José María Vigil, Vicente Riva Palacio y Adalberto Esteva (Romero, 2008: 116-117) y admitida, con diez poemas, en la modernista Revista Azul (Romero, 2015: 147), así como autora de una novela por entregas, El espejo de Amarilis. Novela de costumbres mexicanas, publicada en México en 1902 y rescatada recientemente. ${ }^{23}$

\footnotetext{
${ }^{22}$ Fórmula o guiño que utiliza Bazant (2013b: 34; las cursivas son de la autora), con benévola ironía, para aludir al "férreo temperamento capaz de mover montañas" que caracterizaba a la maestra mexicana (36).

${ }^{23}$ Todavía en 1991, Ana Rosa Domenella, coordinadora junto con Nora Pasternac de la publicación que resultó de las investigaciones del Taller de Narrativa Femenina Mexicana del Programa Interdisciplinario de Estudios de la Mujer (PIEM, Colegio de México), declaraba: "una novela — que no fue posible localizar - llamada El espejo de Amarilis" (20). Finalmente, la novela de Méndez se incluyó en el tomo I de sus obras completas (véase Bazant, 2011).
} 
Pero quizá el ejemplo de María Enriqueta Camarillo de Pereyra sirva mejor para nuestro propósito: llámese "mediación"24 o "patronazgo masculino" (Fernández, 2015: 83) es evidente que hay que contarlos entre sus prerrogativas. Había estallado la Primera Guerra Mundial cuando, después de una estadía en Suiza de cerca de dos años (véase Soltero: 25 y 30), Camarillo se instaló en Madrid, siguiendo a Carlos Pereyra, su marido, importante historiador mexicano y diplomático en diversos países europeos. En la ciudad española, donde permanecieron durante treinta años aproximadamente, la escritora publicó la mayoría de sus obras y contó "con valiosísimas credenciales de la pluma de Rubén Darío, la Pardo Bazán, Díez-Canedo, Blanco Fombona, Torres Bodet, Henríquez Ureña, etc." (Martínez y Mejías: 139). Los cinco tomos de la serie Rosas de la infancia le fueron solicitados a Camarillo en 1912 por la propia casa Vda. de Ch. Bouret, como lo recuerda la autora en el volumen reeditado por Patria en 1962: "la editorial me pidió que escribiera una colección de libros de lectura dedicados a la niñez mexicana" (citada en Hurtado: 4). Resultó ser una apuesta editorial rentable, además de circunscribirse al feminizado terreno pedagógico y escolar en el que la casa Bouret ejercía como líder: se contabilizan más de 120 títulos de "Libros de texto para enseñanza primaria” editados por la casa franco-mexicana Bouret entre 1881 y 1923 (véase Ziga). Altamente moralizadoras, las Rosas de la infancia reafirmaban la permanencia de los valores burgueses y patriarcales, con los que tanto su personalidad como el resto de su creación literaria han quedado vinculados: "Contradictoriamente tímida y famosa, prudente y exitosa, defensora de la domesticidad y [...] escritora profesional mexicana", lejos de molestar "la celosa sensibilidad del sexo opuesto", la obra de María Enriqueta Camarillo, al decir de Esther Hernández Palacios, "no alcanzó a rebasar las fronteras de sus obligados resguardos" (19 y 90, respectivamente).

Sin pretender cuestionar su vívida vocación ni sus positivas dotes literarias, sí debe interpelarnos el encumbramiento crítico unánime en la época - demasiado unánime - de una escritora que, en la década del veinte en México, se retrata como "[p]oetisa inspirada, sin complicaciones ni rebuscamientos, [cuyos] cantos son todo ternura y todo sinceridad", un "espíritu 'sentimental, sensible, sensitivo", que escribe con "diáfana sencillez" ("Escritores...": 58). En Madrid, se estima "una preeminente figura que destaca su silueta poliaspectal en el horizonte americano. Poetisa, novelista y cuentista, María Enriqueta es la melancólica lira dulce y serena si bien estremecida con frecuencia por un patético presentimiento de muerte" (González: 11). Incluso, en París, fue también elogiada como:

poétesse originaire de [Coatepec], qui compte parmi les plus inspirées de la littérature mondiale contemporaine, [...et qui] nous touche par la sentimentalité contenue et dé-

${ }^{24}$ Noción derivada del "mediador masculino" de Rosario Castellanos (15). 


\section{|Dolores Phillipps-López}

licate de ses notations. [P]oétesse exquise, on s'étonnera de trouver sous la plume d'une femme de lettres moderne l'expression émue et émouvante des plus humbles aspects de la vie quotidienne. [...] Maintenant épouse du célèbre historien Carlos Pereyra, [...] elle cultive les vertus domestiques des vieilles familles espagnoles et chante en vers d'une sereine mélancolie la poésie de la grande maison où se déroule la vie, la silencieuse noblesse de certaines heures où l'on médite dans la paix du foyer. ${ }^{25}$

Cunden los estereotipos de género (y de clase) para calificar su obra, suscitando razones para sospechar que su práctica literaria fue significativamente tolerada por inocua: "Muchos de sus contemporáneos [...] le dedicaron estudios, la leyeron, la disfrutaron por sus maneras inofensivas [...], pues cumple el ideal de lo femenino (en la mente masculina)" (Granillo: s. p.).

En el polo opuesto está Betanzo, "conspiradora" o desobediente, pues, al margen de los circuitos convencionales de legitimación, ignoramos si Chanteclair llegó a financiar también la publicación de su primera obra La modelo. La insaciable en la editorial de la Vda. de Ch. Bouret en 1909. La "Propiedad del Editor", inscrita en la portadilla, autoriza incluso a pensar lo contrario. En todo caso, las ansias autoriales y proactivas de Betanzo - ya fueran obstinada búsqueda de figuración literaria o admirable agencia de una escritora en ciernes - llevaron a este primer libro suyo a constar en la vistosa colección de Bouret "Biblioteca de los Novelistas", al lado de algunos best sellers del escritor colombiano José María Vargas Vila y del guatemalteco Enrique Gómez Carrillo. ${ }^{26}$

Ciertamente, los casos de relegación literaria en la producción del modernismo, como el evocado de Francisca Betanzo, no son sólo femeninos ni tampoco, desde luego, mexicanos. Sin embargo, aunque exigua y liminar, su incursión en la literatura femenina mexicana de principios del siglo xx - performativa y heterodoxa - merece ser consignada y difundida por la apropiación narrativa funcional, impugnadora de los estereotipos de género vigentes en los ámbitos de lo político, profesional y corpo-

25 “poetisa originaria de [Coatepec], que se cuenta entre las más inspiradas de la literatura mundial contemporánea, [...y que] nos afecta por la sentimentalidad contenida y delicada de sus notaciones. [P]oetisa exquisita, nos extrañaremos de encontrar bajo la pluma de una mujer de letras moderna la expresión emocionada y emocionante de los más humildes aspectos de la vida cotidiana. [...] Ahora esposa del célebre historiador Carlos Pereyra, [...] cultiva las virtudes domésticas de las antiguas familias españolas y canta en versos de serena melancolía la poesía de la casa grande en la que se desenvuelve la vida, la silente nobleza de ciertas horas en las que se medita en la paz del hogar" (Le Clerc: 3).

${ }^{26}$ La casa Bouret llegó a publicar 19 libros de Vargas Vila, entre los cuales 11 lograron reediciones (véase Villegas: 168-171). De Gómez Carrillo se conocen por lo menos dos títulos publicados en la "Biblioteca de los novelistas" de Bouret: La bohemia sentimental (1911) y Maravillas (1917). 
ral, así como por sus peculiares vicisitudes editoriales, en particular, por la relativa falta de prestigio que supone la edición de sus tres libros por cuenta propia, y, también, por la recepción crítica evasiva, cuando no adversa, de sus novelas y novelas cortas - necesitadas de reedición - . Todo lo anterior documenta una modalidad de insurgencia poco frecuente en aquel contexto, que está a la espera de ser estudiada. ${ }^{27}$

\section{Bibliografía}

\section{Les Annales Politiques et Littéraires}

Paris: (2 janvier 1916), 25. Consultado en: https://gallica.bnf.fr/html/und/presse-et-revues/ presse-et-revues [01/04/19].

Bazant, Mílada (coordinadora)

Laura Méndez de Cuenca: su herencia cultural. Tomo I. Estudio introductorio de Ana Rosa Domenella y Luzelena Gutiérrez de Velasco. México: El Colegio Mexiquense/Siglo XXI, 2011.

BAZANT, Mílada (editora)

Laura Méndez de Cuenca (1853-1928). Mujer indómita y moderna: vida cotidiana y entorno educativo. $3^{a}$ edición. Zinacantepec, Estado de México: El Colegio Mexiquense, 2013a.

Bazant, Mílada

"Una musa de la modernidad: Laura Méndez de Cuenca (1853-1928)", en Revista de Historia de la Educación Latinoamericana, volumen 15, número 21 (julio-diciembre de 2013b), 19-50.

"Bibliografía. Libros y Folletos recibidos en esta Redacción"

El Tiempo (viernes 2 de diciembre de 1910), 8. Consultado en: http://www.hndm.unam. mx/index.php/es/ [16/04/19].

BOtreL, Jean-François

La 'Sociedad de Ediciones Literarias y Artísticas-Librería Paul Ollendorff'. Talence: Université de Bordeaux, 1970. Versión española en Jean-François Botrel. Libros, prensa y lectura en la España del siglo XIX. Madrid: Fundación Germán Sánchez Ruipérez, 1993, 578-662.

"La librairie 'espagnole' en France au XIx ${ }^{\mathrm{e}}$ siècle", en Jean-Yves Mollier (director). Le Commerce de la librairie en France au XIXe siècle (1798-1914). Paris: IMEC/Maison des Sciences de l'Homme, 1997, 287-297.

"L’exportation des livres et modèles éditoriaux français en Espagne et en Amérique latine (1814-1914)", en Jacques Michon y Jean-Yves Mollier (directores). Les mutations du livre et de

${ }^{27}$ Además de la temprana tesis de maestría de Danielson (1937), presentada en la Universidad de Minnesota, y de nuestro artículo (Phillipps-López, 2001), conocemos dos acercamientos recientes a la obra de esta narradora: Martínez Suárez (2012) y García (2017). 


\section{|Dolores Phillipps-López}

l'édition dans le monde du XVIIt siècle à l'an 2000. Québec: Presses de l'Université Laval/L'Harmattan, 2001, 219-240.

Brussot, Martin

"Südamerikanischer Brief", en Das Literarische Echo (halbmonatschrift für Literaturfreunde), Heft 12 (15 März 1922), 752-756.

[Camarillo y Roa de Pereyra], María Enriqueta

Rosas de la Infancia. Lecturas para los niños. Libro primero. Ilustraciones de Gedovius. México/ París: Librería de la Vda. de Ch. Bouret, 1913.

Castellanos, Rosario

Mujer que sabe latín. México: Diana, 1979.

Chanteclair [Francisca Betanzo]

La Modelo. La Insaciable. París/México: Biblioteca de los Novelistas, Librería de la Vda. de Ch. Bouret, 1909.

La peña del infortunio. Paris: Paul Ollendorff, 1910.

Asceta y suicida. Paris: Paul Ollendorff (suscrita en "París, febrero de 1911 ”), 1912 (febrero).

Brumas alcohólicas, seguida de $A$ sangre y fuego. Barcelona: Francisco Granada (suscrita en "Barcelona y agosto 26 de 1909"), ¿1912?

Cooper-Richet, Diana

"París y los ambos mundos: une capitale au cœur du dispositif de production et de mise en circulation de libres et de journaux, en espagnol, au XIX siècle", en Cahiers des Amériques Latines. Paris: IHEAL, números 72-73 (2013), 201-220.

DANieLson, Gertrude B.

"Social aspects of Mexico in the novels of Francisca Betanzo". MA Thesis. Minnesota: University of Minnesota, 1937.

Domenella, Ana Rosa y Nora Pasternac (editoras)

Las voces olvidadas. Antología crítica de narradoras mexicanas nacidas en el siglo XIX. México: El Colegio de México, 1991.

Domenella, Ana Rosa y Luzelena Gutiérrez de Velasco

"Laura Méndez de Cuenca. Escritora mexicana de la otra vuelta de siglo", en Arrabal, número 4 (2002), 191-201.

"Escritores mexicanos contemporáneos. María Enriqueta"

Biblos (10 de abril de 1920), 58. Consultado en: http://www.hndm.unam.mx/index.php/ es/ [16/04/19].

66 (an)ecdótica vol. IV, núm. 1, enero-junio 2020 
La Esquella de la Torratxa: Periódich Satírich, Humoristich, Ilustraty Literari

Barcelona: any 31, número 1601 (3 de setembre de 1909), 583. Consultado en: https:// arca.bnc.cat/arcabib_pro/es/catalogo_imagenes/grupo.do?path=1206849 [16/04/19].

FERnÁNDEZ, Ángel José

"Los editores de Laura Méndez de Cuenca", en Nueva Revista de Filología Hispánica, volumen LXII, número 1 (2014), 159-179.

FERNÁNDEZ, Pura

"El monopolio del mercado internacional de impresos en castellano en el siglo XIx: Francia, España y 'la ruta' de Hispanoamérica”, en Bulletin Hispanique, tomo 100, número 1 (1998), 165-190.

FERnández, Pura (editora)

No hay nación para este sexo. La Re(d)pública trasatlántica de las Letras: escritoras españolas y latinoamericanas (1824-1936). Madrid/Frankfurt: Iberoamericana/Vervuert, 2015.

"Francisca Betanzo"

Enciclopedia de la literatura en México. México: Secretaría de Cultura/Fundación para las Letras Mexicanas. Consultado en: http://www.elem.mx/autor/datos/1254 [04/04/19].

FRANCO, Jean

Las conspiradoras. La representación de la mujer en México. México: El Colegio de México/Fondo de Gultura Económica, 1994.

García, Alejandro

"La utopía del deseo profano: Francisca Betanzo", en Pulso Académico. México: Universidad Nacional Autónoma de México-Plantel Naucalpan, número 8 (mayo de 2017), 67-68.

García Barragán, María Guadalupe

El naturalismo literario en México. México: Universidad Nacional Autónoma de México, 1993.

GLanTz, Margo

"El periodismo del siglo xix en México", en Revista de la Universidad de México, número 92, sección VI (octubre de 2011), s. p. Consultado en: http://www.revistadelauniversidad. unam.mx/9211/glantz/92glantz3.html [16/04/19].

González Ruano, César

"Poetisas americanas. María Enriqueta”, en Castilla, número 56 (12 de marzo de 1925), 11.

Granillo VÁzQuez, Lilia

"Las máscaras de una niña mexicana: rosas, amores y dolores de María Enriqueta", en María Enriqueta Camarillo y Roa de Pereyra. Rincones románticos. Una antología general. Selección y estudio preliminar de Esther Hernández Palacios. Ensayos críticos de Laura Guerrero Guadarrama y Lilia Granillo Vázquez. Edición y cronología de Germán Ceballos Gutiérrez y Héctor Miguel Sánchez Rodríguez. México: Fondo de Cultura Económica/ 


\section{|Dolores Phillipps-López}

Universidad Nacional Autónoma de México/Fundación para las Letras Mexicanas, 2018, s. p. [edición electrónica].

HaBIB, Claude

"La femme plumée", en Femmes et institutions littéraires. Paris: Université de Paris VII, 1984.

Hernández de López, Ana María

El Mundial Magazine de Rubén Darío. Madrid: Beramar, 1989.

Hernández Palacios, Esther (coordinadora)

Creadores veracruzanos. Diez semblanzas. Xalapa: Gobierno del Estado de Veracruz, Secretaría de Educación del Estado de Veracruz/Universidad Veracruzana, 2010.

HiNTERHÄUSER, Hans

"Mujeres prerrafaelitas", en Fin de siglo: figuras y mitos. Madrid: Taurus, 1980, 91-121.

Hurtado Tomás, Patricia

"Rosas de la infancia: una historia que contar", en IX Congreso Nacional de Investigación Educativa, Mérida/Yucatán (5-9 de noviembre de 2007). Consultado en: www.comie. org.mx/congreso/memoriaelectronica/v09/ponencias/at09/PRE1 178941615.pdf [03/10/19].

IGUínIz, Juan Bautista

Bibliografia de novelistas mexicanos. México: Secretaría de Relaciones Exteriores, 1926.

INSEE, Institut National de la Statistique et des Etudes Economiques

Consultado en: https://www.insee.fr/fr/information/2417794 [01/04/19].

Le Clere de la Herverie, Bernard

"Une poétesse mexicaine", en Le Gaulois (mercredi 22 août 1923), 3-4. Consultado en: https://gallica.bnf.fr/html/und/presse-et-revues/presse-et-revues [01/04/19].

"Libros hispano-americanos"

Mundial Magazine. Dirección literaria de Rubén Darío. Paris: Leo Merelo \& Guido Fils, volumen II, número 12 (abril de 1912), 590. Consultado en: https://gallica.bnf.fr/html/ und/presse-et-revues/presse-et-revues [01/04/19].

LUDMER, Josefina

"Las tretas del débil", en Patricia E. González y Eliana Ortega (editoras). La sartén por el mango. Puerto Rico: Huracán, 1985, 47-59.

Martínez Gómez, Juana y Almudena Mejías Alonso

Hispanoamericanas en Madrid (1800-1936). Madrid: Dirección General de la Mujer/Horas, 1994. 
Martínez SuÁrez, José Luis

"Francisca Betanzo: una escritora naturalista olvidada", en Carlomagno Sol (editor). Textos marginados y escritores raros mexicanos, siglo XIX. Valladolid: Universitas Castellae, 2012, 149-158.

Méndez de Cuenca, Laura

Simplezas. Paris: Paul Ollendorff, 1910.

MolLier, Jean-Yves

Histoire du capitalisme d'édition 1880-1920. Paris: Fayard, 1988.

Molloy, Sylvia

La diffusion de la littérature hispano-américaine en France au XX siècle. Paris: Presses Universitaires de France, 1972 (Série "Recherches", 68).

Montero Sánchez, Susana A.

La construcción simbólica de las identidades sociales. Un análisis a través de la literatura mexicana del siglo XIX. México: Universidad Nacional Autónoma de México, Programa Universitario de Estudios de Género, Centro Coordinador y Difusor de Estudios Latinoamericanos/Plaza y Valdés, 2002.

Phillipps-López, Dolores

"Salir del anonimato: el inseguro camino de Francisca Betanzo", en H. Hermans y Catherine Raffi-Béroud (compiladores). La mujer mexicana en el dominio público y en el privado. Groningen: University of Groningen, Centro de Estudios Mexicanos, 2001, 53-64.

Romero Chumacero, Leticia

"Laura Méndez de Cuenca: el canon de la vida literaria decimonónica mexicana", en Relaciones. Estudios de Historia y Sociedad, volumen XXIX, número 113 (invierno de 2008), 107-141.

"Un impulso de solidaridad: el feminismo de Laura Méndez de Cuenca", en Mílada Bazant (editora). Laura Méndez de Cuenca: su herencia cultural. Tomo III. México: El Colegio Mexiquense/Siglo XXI, 2011, 189-204.

Una historia de zozobra y desconcierto. La recepción de las primeras escritoras profesionales en México (1867-1910). México: Universidad Autónoma de la Ciudad de México/Gedisa, 2015.

\section{Servén Díez, Carmen}

"Concepción Gimeno de Flaquer (1850-1919)", en Escritoras españolas en la prensa, 1868-1936 [portal digital], s. f., s. p. Consultado en: http://www.escritorasenlaprensa.es/concepciongimeno-de-flaquer/ [01/04/19].

Soltero Sánchez, Evangelina

"María Enriqueta Camarillo: la obra narrativa de una mexicana en Madrid". Tesis de doctorado. Madrid: Universidad Complutense de Madrid, 2002. Consultado en: https:// eprints.ucm.es/4443/1/ucm-t26169.pdf [01/04/19]. 


\section{|Dolores Phillipps-López}

\section{SuÁREZ DE LA TORRE, Laura}

"Tejer redes, hacer negocios: la librería internacional Rosa (1818-1850), su presencia comercial e injerencia cultural en México", en Lise Andries y Laura Suárez de la Torre (coordinadoras). Impressions du Mexique et de France. México: Instituto Mora, 2009, 87-114.

Tenreiro, Ramón María

"Simplezas", en La Lectura. Revista de Ciencias y de Artes. Madrid, año X, número 117 (septiembre de 1910), 295-296. Consultado en: http://hemerotecadigital.bne.es/details.vm?q=id: 0002631544\&lang $=$ en $[01 / 04 / 19]$.

"Velada en Tehuacán"

La voz de México (20 de septiembre de 1900), 3. Consultado en: http://www.hndm.unam. $\mathrm{mx} /$ index.php/es/ [04/04/19].

Villegas, Jean-Claude

La littérature hispano-américaine publiée en France, 1900-1980. Paris: Bibliothèque Nationale, 1986.

Ziga Espinosa, Francisco

"Bibliografía pedagógica. Libros de texto para enseñanza primaria: 1850-1970. I. Libros de Lectura", en Boletín del Instituto de Investigaciones Bibliográficas. México: Universidad Nacional Autónoma de México (enero-diciembre de 1975), 111-225. 